\title{
SYNOPSIS
}

NeWS

$\bullet$

ANALYSIS

- Practice

Pharmaceutical Regulations

\section{Canada signs agreements to potentially share drug information with the US and Australia}

Health Canada hopes a new information sharing agreement with Australia will result in faster drug approvals in both countries, but critics say it compounds the lack of transparency surrounding drug approvals.

Signed in April, the memorandum of understanding allows Canada and Australia to share information, including plant inspection reports, clinical trial results and post-market information, that the countries solicit from pharmaceutical companies applying for approval to market their products.

The deal was negotiated between Health Canada's Health Products and Food Branch and the Therapeutic Goods Administration in the Department of Health and Ageing in Australia.

In November 2003, Canada signed a similar agreement with the US Food and Drug Administration. Judith Lockett, Director-General of Health Canada's Office of Regulatory and International Affairs, calls the agreements "extremely successful," but says this is still a new process. "With the US, and very much Australia, we're still in the starting gates with information sharing."

Lockett says Health Canada will continue to do its own testing, but once it is comfortable with the Australian system, the 2 countries may work on joint reviews. "There are no specific plans at this time," she added.

"We really need to get to the stage where we [examine] a few different types of drugs and that will take a little time."

Sharing data has obvious benefits, Lockett says. "Really, it means we have access to a much richer, broader base of information than if we were using Canadian information only."

Pharma-watchdog Dr. Joel Lexchin, an associate professor in York University's school of health policy and management, is more cautious about suporting the agreement.

Lexchin, who has worked in Australia, says its regulatory standards are "quite comparable." His major concern about the agreement is its lack of transparency, since any information received from Australia will be treated as confidential and proprietary, to protect the drug companies' interests.

"That just makes it more difficult for consumers, for the medical community to know how drugs were approved, how the data were assessed, and even what data were assessed," Lexchin says. "If that was resolved, then I think this sort of thing would be a significant plus."

Colleen Fuller, president of PharmaWatch, says too much of what Health Canada does is confidential and lacks public consultation. "So why, when they're building to an agreement this high-level, is this the first I've heard of it?"

Some information that will be exchanged, such as post-market surveillance of drugs, is too important to the public to keep secret, says Fuller. "In Canada, there has been some controversy over how the Therapeutic Products Directorate has applied confidentiality ... in this document, it appears a lot of that information is not going to be shared with the public."

David U, president of the Institute for Safe Medication Practices Canada, says he is glad to see more attention being paid to post-market surveillance.

"Health Canada should be playing a bigger role in the

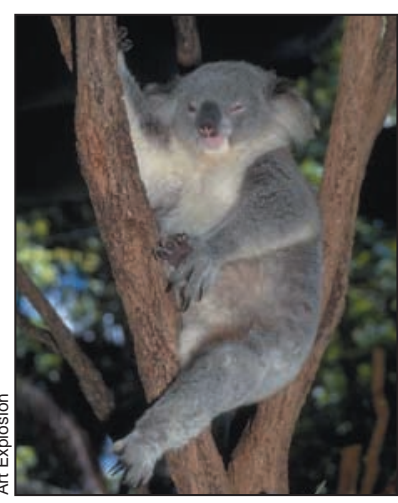

Share bear: Aussies and Canucks collaborate post-market field, that's something I'd like to see. But we seem to be moving along in that direction."

As long as both countries run their systems to the same high standards, information sharing just makes sense, says Lockett. "Australia is one of 5 leading countries where we can say we have comparable standards ... if all 5 of us are reviewing a drug at exactly the same time and we're coming to the same conclusions in the end ... [then] why aren't we doing this together?" she asks.

"But it's far too soon in the process to split it up and find Canada in a position to accept the results produced by another country without having any idea of how their system works." Dan Blouin, Ottawa 